\title{
Beta-Thalassaemia Intermedia: Evaluation of Endocrine and Bone Complications
}

\author{
M. Baldini, ${ }^{1}$ A. Marcon, ${ }^{1}$ R. Cassin, ${ }^{2}$ F. M. Ulivieri, ${ }^{3}$ \\ D. Spinelli, ${ }^{2}$ M. D. Cappellini, ${ }^{1,2}$ and G. Graziadei ${ }^{1}$ \\ ${ }^{1}$ Rare Diseases Center, Department of Medicine and Medical Specialities, \\ Ca' Granda Foundation IRCCS Ospedale Maggiore Policlinico, 20122 Milan, Italy \\ ${ }^{2}$ Department of Clinical Sciences and Community Health, University of Milan, Via F. Sforza, 20122 Milan, Italy \\ ${ }^{3}$ Nuclear Medicine, Bone Metabolic Unit, Ca' Granda Foundation IRCCS Ospedale Maggiore Policlinico, 20122 Milan, Italy
}

Correspondence should be addressed to G. Graziadei; giovanna.graziadei@policlinico.mi.it

Received 4 April 2014; Revised 11 June 2014; Accepted 16 June 2014; Published 7 July 2014

Academic Editor: Paolo Ricchi

Copyright (C) 2014 M. Baldini et al. This is an open access article distributed under the Creative Commons Attribution License, which permits unrestricted use, distribution, and reproduction in any medium, provided the original work is properly cited.

Objective. Data about endocrine and bone disease in nontransfusion-dependent thalassaemia (NTDT) is scanty. The aim of our study was to evaluate these complications in $\beta$-TI adult patients. Methods. We studied retrospectively $70 \beta$-TI patients with mean followup of 20 years. Data recorded included age, gender, haemoglobin and ferritin levels, biochemical and endocrine tests, liver iron concentration (LIC) from $T 2^{*}$, transfusion regimen, iron chelation, hydroxyurea, splenectomy, and bone mineralization by dual X-ray absorptiometry. Results. Thirty-seven (53\%) males and 33 (47\%) females were studied, with mean age $41 \pm 12$ years, mean haemoglobin $9.2 \pm 1.5 \mathrm{~g} / \mathrm{dL}$, median ferritin 537 (range 14-4893), and mean LIC $7.6 \pm 6.4 \mathrm{mg}$ Fe/g dw. Thirty-three patients (47\%) had been transfused, occasionally $(24 / 33 ; 73 \%)$ or regularly $(9 / 33 ; 27 \%) ; 37 / 70(53 \%)$ had never been transfused; $34 / 70$ patients had been splenectomized (49\%); 39 (56\%) were on chelation therapy; and 11 (16\%) were on hydroxyurea. Endocrinopathies were found in 15 patients (21\%): 10 hypothyroidism, 3 hypogonadism, 2 impaired glucose tolerance (IGT), and one diabetes. Bone disease was observed in 53/70 (76\%) patients, osteoporosis in 26/53 (49\%), and osteopenia in 27/53 (51\%). Discussion and Conclusions. Bone disease was found in most patients in our study, while endocrinopathies were highly uncommon, especially hypogonadism. We speculate that low iron burden may protect against endocrinopathy development.

\section{Introduction}

Beta-thalassaemia intermedia ( $\beta$-TI) is a form of NTDT encompassing patients who do not require regular transfusions throughout life, although they may be needed occasionally or even frequently in certain clinical conditions $[1,2]$. These patients spontaneously maintain $\mathrm{Hb}$ levels $7-10 \mathrm{~g} / \mathrm{dL}$ and show different levels of splenomegaly and iron overload.

Beta-TI patients show clinical pictures of intermediate severity between the asymptomatic carrier (Thalassaemia Minor) and the transfusion-dependent thalassaemia patients (Thalassaemia Major). The association of mild, moderate, and severe $\beta$-mutations as well as association of triplication/multiplication of $\alpha$-globin genes can be responsible for wide spectrum of genotypes, and a genotype/phenotype correlation has been observed.
However, several genetic as well as environmental factors can modify clinical expression. The genes affecting the globin chain production are recognized as primary and secondary modifiers, but several other conditions, called tertiary modifiers, can affect the clinical expression, such as the coinheritance of hereditary haemochromatosis or Gilbert syndrome, or alterations of genes involved in iron absorption, bone metabolism, or susceptibility to infections [3]. There is increasing evidence that bone disease may be modified by polymorphisms at loci that are involved in bone metabolism, including the genes for the vitamin $\mathrm{D}$ receptor, collagen, and the oestrogen receptor [4-7]. Moreover, varying availability of medical care can influence the outcome of $\beta$-TI patients.

Endocrine complications are less commonly seen in patients with NTDT than in those with more severe forms 
of thalassemia ( $\beta$-TM and/or severe forms of haemoglobin $\mathrm{E} / \beta$-thalassaemia) $[1,8-12]$.

Nonetheless, $\beta$-TI patients remain at risk of morbidity from endocrine gland and bone pathology, associated with bone pain and fractures [3]. An increased risk of developing several complications, including diabetes mellitus, hypothyroidism, hypoparathyroidism, hypogonadism, and osteoporosis, has been reported in association with higher liver iron concentration (LIC) values or serum ferritin levels as the patients advance in age [13-17]. Conversely, from observational studies lower rates of the same morbidities were associated with iron chelation therapy [11].

As in patients with $\beta$-TM [18], the pathophysiology of endocrinopathies and low bone mineral density in patients with $\beta$-TI is probably multifactorial; ineffective erythropoiesis and expansion of the erythron in the bone marrow are directly implicated $[1,19,20]$ as well as low foetal haemoglobin, splenectomy, and hydroxyurea therapy $[14,19$, 21].

In view of the limited data on endocrinopathy and bone disease prevalence in NTDT, we evaluated these complications in a group of $\beta$-TI adult patients.

\section{Patients and Methods}

In a retrospective study, $70 \beta$-TI adult patients with a mean followup of 20 years were investigated. All patients were followed up at the Hereditary Anaemia Centre of Fondazione IRCCS Ca' Granda Ospedale Maggiore Policlinico of Milan. The study was in adherence to the tenets of the Declaration of Helsinki and approval from the local ethics committee was obtained.

Disease history and systemic treatment, if any, were recorded for all patients including age, gender, haemoglobin and ferritin levels, biochemical and endocrine tests, bone metabolism indices, transfusion regimen, chelation, hydroxyurea therapy, bone specific treatment, and splenectomy.

Patients were considered occasionally transfused when the number of transfusions was $<6$ per year.

Liver iron concentration (LIC) was derived from $\mathrm{T} 2{ }^{*}$ from magnetic resonance imaging (Scanner MRI 1,5 Tesla Avanto Siemens, Enlargen - software CMR Tools, Imperial College, London) according to the formula $[1 /(\mathrm{T} 2 * / 1000)] \times$ $0.0254+0.202[21]$.

All patients underwent bone densitometry scan performed by dual X-ray photon absorptiometry (Hologic Bone Densitometer QDR Discovery A, Version 12.7.3.1 WALTHAM, MA, USA) at the lumbar spine and femur. The bone mineral density values were expressed as $T$ - and $Z$ scores; the $T$-score was calculated as a standard deviation score (SDS) from a normal reference population database, while the $Z$-score was calculated as an SDS from an ageand sex-matched population. Data were classified according to the WHO report (WHO Technical Report, ISCD Official Position Paper 2007): $T$-score $>-1$ : normal, $T$-score between -1 and -2.5 : low bone density (osteopenia), and $T$-score < -2.5 : osteoporosis.
Data are presented as means and standard deviation or median and range as appropriate.

\section{Results}

Among 70 patients, 37 (53\%) were males and 33 (47\%) were females; mean age was $41 \pm 12$ years and mean of haemoglobin levels was $9.2 \pm 1.5 \mathrm{~g} / \mathrm{dL}$. Median ferritin was 537 (range 14-4893) ng/mL and mean LIC $7.6 \pm 6.4 \mathrm{mg} \mathrm{Fe} / \mathrm{g}$ dw. Eleven patients $(16 \%)$ were anti-HCV antibody positive, and among them 6 (55\%) were HCV-RNA positive. Splenectomy had been performed in 34 out of 70 patients (49\%) and 13 patients (18\%) had a history of bone fractures (2 spontaneous and 11 following traumas).

Regarding patient treatment, 37/70 (53\%) had never been transfused and 33 (47\%) had been occasionally $(24 / 33 ; 73 \%)$ or regularly $(9 / 33 ; 27 \%)$ transfused. The patients in the latter group were considered NTDT patients because of the regular transfusion regimen that did not start in childhood but starts later, after an occasional event (pregnancy, surgery, infection, ...), or because of clinical complications, such as heart failure and fatigue with very low $\mathrm{Hb}$ levels leading to poor quality of life. Moreover, the mean transfusional range was 40 days.

Thirty-nine patients (56\%) were on chelation therapy and $11(16 \%)$ on hydroxyurea. Hormone defects were corrected with replacement therapy in all cases except one, due to clinical contraindications to sex steroid treatment. Four patients $(6 \%)$ were on bisphosphonate, $5(7 \%)$ on calcium + vitamin D supplementation, 2 (3\%) on calcium alone, and 16 (23\%) on vitamin D alone.

Characteristics of the population are summarized in Table 1.

Only 15 out of 70 patients (21\%) were diagnosed with endocrinopathy: 10 had hypothyroidism (5 of them were subclinical and did not require therapy), 3 hypogonadism, 2 impaired glucose tolerance (IGT), and one diabetes. Among them, only one patient presented two endocrine complications associated (hypogonadism and diabetes). None of the patients presented with hypoparathyroidism. Vitamin D deficiency was present in 49 patients (70\%).

Bone disease was observed in $53(76 \%)$ patients, osteoporosis in 26, and osteopenia in $27 \beta$-TI (Table 2 ).

In the group of patients with osteoporosis, 7 of them (10\%) had involvement of both vertebral and femoral sites, $18(26 \%)$ presented only vertebral osteoporosis, and one patient (1\%) only had femoral osteoporosis. In the group of patients with osteopenia, 15 (21\%) had involvement of both sites; 8 (11\%) only had involvement of the vertebral site and $4(6 \%)$ only had involvement of the femoral site. Among the 5 patients with selective involvement of the femoral site (cortical bone disease), BMD was reduced both at the femoral neck and at total femoral scan.

\section{Discussion}

Endocrine data in $\beta$-TI patients is scanty in the literature. The biggest problem with $\beta$-TI patients is the wide heterogeneity of the genotypes and of clinical picture, covering a broad 
TABLE 1: Characteristics of the population.

\begin{tabular}{lc}
\hline Parameter & Values \\
\hline Male (number (\%)) & $37 / 70(53)$ \\
Female (number (\%)) & $33 / 70(47)$ \\
Age (years \pm SD) & $41 \pm 12$ \\
$\mathrm{Hb}(\mathrm{g} / \mathrm{dL} \pm \mathrm{SD})$ & $9.2 \pm 1.5$ \\
Ferritin (ng/mL (range)) & $537^{*}(14-4893)$ \\
LIC (mg Fe/g dw \pm SD) & $7.6 \pm 6.4$ \\
Anti-HCV positive (number (\%)) & $11 / 70(16)$ \\
HCV-RNA positive (number (\%)) & $6 / 11(55)$ \\
Splenectomy (number (\%)) & $34 / 70(49)$ \\
Transfusion therapy (number (\%)) & \\
$\quad$ Never & $37 / 70(53)$ \\
Occasionally & $24 / 70(34)$ \\
$\quad$ Regularly & $9 / 70(13)$ \\
Chelation therapy (number (\%)) & $39 / 70(56)$ \\
Hydroxyurea therapy (number (\%)) & $11 / 70(16)$ \\
Hormone replacement therapy (number (\%)) & $2 / 70(3)$ \\
Levothyroxine therapy (number (\%)) & $5 / 70(7)$ \\
Bisphosphonate (number (\%)) & $4 / 70(6)$ \\
Calcium + vitamin D (number (\%)) & $5 / 70(7)$ \\
Calcium alone (number (\%)) & $2 / 70(3)$ \\
Vitamin D alone (number (\%)) & $16 / 70(23)$ \\
\hline
\end{tabular}

${ }^{*}$ median and range.

TABLE 2: Osteopenia/osteoporosis in $70 \beta$-TI adult patients.

\begin{tabular}{|c|c|c|c|c|c|}
\hline \multirow{7}{*}{ Osteoporosis } & \multirow{7}{*}{$26 / 70$} & Vertebral & $18 / 26$ & & \\
\hline & & & & Total & 0 \\
\hline & & Femoral & $1 / 26$ & Neck & 0 \\
\hline & & & & Both & $1 / 1$ \\
\hline & & & & Total & $1 / 7$ \\
\hline & & Both & $7 / 26$ & Neck & $2 / 7$ \\
\hline & & & & Both & $4 / 7$ \\
\hline \multirow{7}{*}{ Osteopenia } & \multirow{7}{*}{$27 / 70$} & Vertebral & $8 / 27$ & & \\
\hline & & & & Total & 0 \\
\hline & & Femoral & $4 / 27$ & Neck & 0 \\
\hline & & & & Both & $4 / 4$ \\
\hline & & & & Total & $3 / 15$ \\
\hline & & Both & $15 / 27$ & Neck & $3 / 15$ \\
\hline & & & & Both & $9 / 15$ \\
\hline Normal & $17 / 70$ & & & & \\
\hline
\end{tabular}

spectrum from good general health even in adult age to a compromised condition with early growth retardation and skeletal deformities, due to intense ineffective erythropoiesis and erythroid bone marrow hypertrophy $[22,23]$. In such a complex scenario, which also comprises differing genetic patterns and organ damage, the identification of genetic and/or clinical risk factors for endocrinopathy or osteoporosis is a real challenge. Further, bone and endocrine state have been less studied in $\beta$-TI than in $\beta$-TM patients.

In our patients with $\beta$-TI, the prevalence of endocrinopathy does not appear significantly different from that expected in the general nonthalassaemic population [24-26], while bone demineralization, even severe, is a highly common finding, affecting more than two thirds of patients. The prevalence of osteopenia and osteoporosis is very similar, and trabecular bone is predominantly involved regardless of bone disease severity. These findings are in line with previous literature, as bone abnormalities typical of $\beta$-TM have been described as often present in $\beta$-TI, and sometimes more marked, starting from the first decade of life. An increased risk of fractures, even spontaneous or following minor traumas, has also been reported; this has been ascribed to osteoporosis as well as to medullary overgrowth due to erythroid stress, aiming to compensate for anaemia [27]. When fractures are recurrent, some authors recommend transfusion therapy [28]. In a large thalassaemic population from North America, Vogiatzi et al. described a $12 \%$ prevalence of fractures in $\beta$-TI patients, increasing with age and with use of sex hormone replacement [29], that is, with hypogonadism.

An additional negative influence on bone condition can be caused by the association between $\beta$-TI and $25-\mathrm{OH}$ vitamin $\mathrm{D}$ deficiency, frequently reported in thalassaemic populations $[12,29]$. In our group, vitamin $D$ deficiency was demonstrated in the majority of the $\beta$-TI patients, $35 \%$ of whom were compliant with cholecalciferol supplementation prescribed at the usually recommended dose of $800 \mathrm{IU} /$ day [30]. Nonetheless, bone demineralization of varying severity and low $25 \mathrm{OH}$-vitamin D levels were present in most cases. The persistence of inadequate vitamin D status despite supplementation and the possibility of reduced skin production or impaired liver metabolism of the vitamin have been previously described in $\beta$-TM patients [31, 32]. If $\beta$-TI patients had similarly increased vitamin $\mathrm{D}$ requirements in order to produce adequate $25-\mathrm{OH} \mathrm{D}$ serum levels, they would need high dose supplementation, as indicated by Soliman et al., recommending repletion therapy with $50000 \mathrm{IU}$ of vitamin D weekly for 8 weeks, followed by maintenance with doses up to $50000 \mathrm{IU}$ per month [32].

Unlike $\beta$-TM, endocrinopathies play a minor role in bone condition in $\beta$-TI. In a previous study from our group, $78.4 \%$ out of $111 \beta$-TM patients were hypogonadic, $17.1 \%$ were hypoparathyroid, and $16.2 \%$ were both hypogonadic and hypoparathyroid, while glucose metabolism was impaired in $40 \%$ of patients (diabetes mellitus in $18 \%$ and IGT in $22 \%$ ) [33]. Conversely, in our $\beta$-TI patients a single endocrine defect was present in merely 15 out of 70 patients (21\%), and only one patient $(0.01 \%)$ had more than one defect.

The low prevalence of endocrine complications in $\beta$-TI has been previously described; however, in our patients the prevalence of single defects differs from previous reports. More precisely, hypogonadism was exceptional in our group; there were no cases of verified infertility, and more than $50 \%$ of our patients had offspring in all cases without induction. In the literature, hypogonadism has been described as the most common endocrine complication in $\beta$-TI patients, with predominant involvement of females $[13,34]$. Moreover, puberty has been described as not infrequently delayed and irregular menses as not unusual, even if generally fertility appeared not to be compromised, with spontaneous conception [3537]. Diabetes and hypothyroidism appear less common in the 
literature than hypogonadism; the Optimal Care study found prevalence of $1.7 \%, 5.7 \%$, and $17 \%$ for diabetes, hypothyroidism, and hypogonadism, respectively [13]. By contrast, the thyroid was the most frequently affected gland among our patients (10 cases, $14 \%$ ), and $24 \%$ of them had antithyroid antibodies positivity; this percentage is in line with the high prevalence of autoimmune hypothyroidism in Italy [38]. The prevalence of glucose metabolism impairment in our patients was similar to values described in the literature, while no patient was affected by hypoparathyroidism.

It is well known that the different endocrine involvement between $\beta$-TI and $\beta$-TM highlights the different impact of iron overload on the two diseases. In effect, severe iron-overload related endocrine dysfunction is universally described in $\beta$-TM, while in $\beta$-TI the pattern of iron overload is preferentially hepatic and it develops gradually throughout life. Compared to the reported data in NTDT [39], our $\beta$-TI patients showed a very low iron burden, expressed as LIC (mean values $7.6 \mathrm{mg} \mathrm{Fe} / \mathrm{g} \mathrm{dw}$ ); this could explain the low prevalence of endocrinopathies, especially regarding the most iron-sensitive cells (gonadotrophs). On the other hand, these LIC values in our series can be ascribed to the nontransfusion-dependent status per se, considering that $>50 \%$ had never been transfused (mean $\mathrm{Hb} 9.8 \mathrm{~g} / \mathrm{dL}$ ), and all were compliant with iron chelation therapy when prescribed. This is in agreement with the reported association between transfusion therapy (either intermittent or regular) and increased risk of endocrinopathy [13]. In fact the 3 patients with hypogonadism in the present group all had high LIC values and had been transfused.

A further important consideration is the good tissue oxygenation due to the satisfactory $\mathrm{Hb}$ levels in our patients, with the mean $\mathrm{Hb}$ in the whole series being $9.2 \mathrm{~g} / \mathrm{dL}$ (evaluating pretransfusion values in regularly or occasionally transfused patients).

Regarding bone mineralization, the group of transfused (both regularly and occasionally) thalassaemic patients showed lower BMD values compared to ones that were not transfused. This finding suggests that when bone damage is established, it persists despite transfusion therapy. In fact, in the group of transfused patients haemoglobin levels had been low for many years before starting transfusional therapy.

We recognize that one limit of our study is the lack of statistical analysis, but this is due to the low prevalence of endocrinopathies, which does not allow any correlation to be drawn. For example, it would be interesting to evaluate if endocrine deficiency can be associated with splenectomy or with hydroxyurea treatment, but this analysis would require a larger population.

For the same reason, we did not divide patients into groups according to transfusion status to avoid an excessive fragmentation of the population.

In view of the scarcity of endocrinological and densitometric data on the $\beta$-TI population in the literature, unlike the well-studied $\beta$-TM patients, our findings warrant further studies to evaluate the impact of transfusion and ironchelation therapy on the outcome of the patients.

\section{Conflict of Interests}

The authors declare that there is no conflict of interests regarding the publication of this paper.

\section{References}

[1] K. M. Musallam, S. Rivella, E. Vichinsky, and E. A. Rachmilewitz, "Non-transfusion-dependent thalassemias," Haematologica, vol. 98, no. 6, pp. 833-844, 2013.

[2] D. J. Weatherall, "The definition and epidemiology of nontransfusion-dependent thalassemia," Blood Reviews, vol. 26, supplement 1, pp. S3-S6, 2012.

[3] D. J. Weatherall, "Phenotype-genotype relationships in monogenic disease: Lessons from the thalassaemias," Nature Reviews Genetics, vol. 2, no. 4, pp. 245-255, 2001.

[4] N. C. Andrews, "Iron homeostasis: insights from genetics and animal models," Nature Reviews Genetics, vol. 1, no. 3, pp. 208$217,2000$.

[5] B. Wonke, "Bone disease in beta-thalassaemia major," British Journal of Haematology, vol. 103, no. 4, pp. 897-901, 1998.

[6] S. Perrotta, M. D. Cappellini, F. Bertoldo et al., "Osteoporosis in $\beta$ thalassaemia major patients: analysis of the genetic background," British Journal of Haematology, vol. 111, pp. 461-466, 2000.

[7] R. D. Pollak, E. Rachmilewitz, A. Blumenfeld, M. Idelson, and A. W. Goldfarb, "Bone mineral metabolism in adults with $\beta$ thalassaemia major and intermedia," British Journal of Haematology, vol. 111, no. 3, pp. 902-907, 2000.

[8] M. D. Cappellini, A. Cohen, A. Eleftheriou, A. Piga, J. Porter, and A. Taher, Guidelines for the Clinical Management of Thalassaemia, Revised, Thalassaemia International Federation, Nicosia, Cyprus, 2nd edition, 2008.

[9] A. T. Taher, K. M. Musallam, V. Viprakasit, J. B. Porter, and M. D. Cappellini, "Iron chelation therapy for non-transfusiondependent thalassemia (NTDT): a status quo," Blood Cells, Molecules \& Diseases, vol. 52, no. 2-3, pp. 88-90, 2014.

[10] N. F. Olivieri, G. M. Muraca, A. O’Donnell, A. Premawardhena, C. Fisher, and D. J. Weatherall, "Studies in haemoglobin E betathalassaemia," British Journal of Haematology, vol. 141, no. 3, pp. 388-397, 2008.

[11] A. Lal, M. L. Goldrich, D. A. Haines, M. Azimi, S. T. Singer, and E. P. Vichinsky, "Heterogeneity of hemoglobin H disease in childhood," The New England Journal of Medicine, vol. 364, no. 8, pp. 710-718, 2011.

[12] O. Sripichai, W. Makarasara, T. Munkongdee et al., "A scoring system for the classification of $\beta$-thalassemia/Hb E disease severity," American Journal of Hematology, vol. 83, no. 6, pp. 482484, 2008.

[13] A. T. Taher, K. M. Musallam, M. Karimi et al., "Overview on practices in thalassemia intermedia management aiming for lowering complication rates across a region of endemicity: the optimal care study," Blood, vol. 115, no. 10, pp. 1886-1892, 2010.

[14] K. M. Musallam, M. D. Cappellini, J. C. Wood et al., "Elevated liver iron concentration is a marker of increased morbidity in patients with $\beta$ thalassemia intermedia," Haematologica, vol. 96, no. 11, pp. 1605-1612, 2011.

[15] K. M. Musallam, M. D. Cappellini, and A. T. Taher, "Evaluation of the $5 \mathrm{mg} / \mathrm{g}$ liver iron concentration threshold and its association with morbidity in patients with $\beta$-thalassemia intermedia," Blood Cells, Molecules, and Diseases, vol. 51, no. 1, pp. 35-38, 2013. 
[16] A. Kurtoglu, E. Kurtoglu, and A. K. Temizkan, "Effect of iron overload on endocrinopathies in patients with beta-thalassaemia major and intermedia," Endokrynologia Polska, vol. 63, no. 4, pp. 260-263, 2012.

[17] A. T. Taher, K. M. Musallam, A. El-Beshlawy et al., "Age-related complications in treatment-naïve patients with thalassaemia intermedia," British Journal of Haematology, vol. 150, no. 4, pp. 486-489, 2010.

[18] R. Haidar, K. M. Musallam, and A. T. Taher, "Bone disease and skeletal complications in patients with $\beta$ thalassemia major," Bone, vol. 48, no. 3, pp. 425-432, 2011.

[19] K. M. Musallam, A. T. Taher, L. Duca, C. Cesaretti, R. Halawi, and M. D. Cappellini, "Levels of growth differentiation factor15 are high and correlate with clinical severity in transfusionindependent patients with beta thalassemia intermedia," Blood Cells, Molecules, and Diseases, vol. 47, no. 4, pp. 232-234, 2011.

[20] S. Rivella, "The role of ineffective erythropoiesis in non-transfusion-dependent thalassemia," Blood Reviews, vol. 26, no. 1, pp. S12-S15, 2012.

[21] K. M. Musallam, V. G. Sankaran, M. D. Cappellini, L. Duca, D. G. Nathan, and A. T. Taher, "Fetal hemoglobin levels and morbidity in untransfused patients with $\beta$-thalassemia intermedia," Blood, vol. 119, no. 2, pp. 364-367, 2012.

[22] A. Cao, P. Moi, and R. Galanello, "Recent advances in beta-thalassemias," Pediatric Reports, vol. 3, no. 2, article E17, 2011.

[23] A. Taher, H. Ismaeel, and M. D. Cappellini, “Thalassemia intermedia: revisited," Blood Cells, Molecules, and Diseases, vol. 37, no. 1, pp. 12-20, 2006.

[24] J. M. Martinez-Jabaloyas, "Hipogonadism. Global epidemiology and transversal relationships," Archivos Españoles de Urología, vol. 66, no. 7, pp. 632-638, 2013.

[25] J. P. Almandoz and H. Gharib, "Hypothyroidism: etiology, diagnosis, and management," Medical Clinics of North America, vol. 96, no. 2, pp. 203-221, 2012.

[26] N. Sarwar, P. Gao, S. R. Seshasai et al., "Diabetes mellitus, fasting blood glucose concentration, and risk of vascular disease: a collaborative meta-analysis of 102 prospective studies," The Lancet, vol. 375, no. 9733, pp. 2215-2222, 2010.

[27] R. Haidar, H. Mhaidli, and A. T. Taher, "Paraspinal extramedullary hematopoiesis in patients with thalassemia intermedia," European Spine Journal, vol. 19, no. 6, pp. 871-878, 2010.

[28] A. Aessopos, M. Kati, and J. Meletis, "Thalassemia intermedia today: should patients regularly receive transfusions?" Transfusion, vol. 47, no. 5, pp. 792-800, 2007.

[29] M. G. Vogiatzi, K. A. Autio, J. E. Mait, R. Schneider, M. Lesser, and P. J. Giardina, "Low bone mineral density in adolescents with $\beta$-thalassemia," Annals of the New York Academy of Sciences, vol. 1054, pp. 462-466, 2005.

[30] R. Vieth, "Why the optimal requirement for Vitamin D3 is probably much higher than what is officially recommended for adults," Journal of Steroid Biochemistry and Molecular Biology, vol. 89-90, pp. 575-579, 2004.

[31] E. B. Fung, C. Aguilar, I. Micaily, D. Haines, and A. Lal, "Treatment of vitamin D deficiency in transfusion-dependent thalassemia," The American Journal of Hematology, vol. 86, no. 10, pp. 871-873, 2011.

[32] A. Soliman, V. de Sanctis, and M. Yassin, "Vitamin D status in thalassemia major: an update," Mediterranean Journal of Hematology and Infectious Diseases, vol. 5, no. 1, Article ID e2013057, 2013.
[33] M. Baldini, S. Forti, A. Marcon et al., "Endocrine and bone disease in appropriately treated adult patients with beta-thalassemia major," Annals of Hematology, vol. 89, no. 12, pp. 12071213, 2010.

[34] A. T. Taher, K. M. Musallam, and A. Inati, "Iron overload: consequences, assessment, and monitoring," Hemoglobin, vol. 33, supplement 1, pp. S46-S57, 2009.

[35] A. H. Nassar, I. M. Usta, J. B. Rechdan, S. Koussa, A. Inati, and A. T. Taher, "Pregnancy in patients with beta-thalassemia intermedia: outcome of mothers and newborns," The American Journal of Hematology, vol. 81, no. 7, pp. 499-502, 2006.

[36] J. Papadimas, D. G. Goulis, E. Mandala et al., "Beta-thalassemia and gonadal axis: a cross-sectional, clinical study in a Greek population," Hormones, vol. 1, pp. 179-187, 2002.

[37] N. Skordis, S. Christou, M. Koliou, N. Pavlides, and M. Angastiniotis, "Fertility in female patients with thalassemia," Journal of Pediatric Endocrinology and Metabolism, vol. 11, supplement 3, pp. 935-943, 1998.

[38] M. Bagnasco, I. Bossert, and G. Pesce, "Stress and autoimmune thyroid diseases," NeuroImmunoModulation, vol. 13, no. 5-6, pp. 309-317, 2007.

[39] A. T. Taher, J. B. Porter, V. Viprakasit et al., "Deferasirox effectively reduces iron overload in non-transfusion-dependent thalassemia (NTDT) patients: 1-year extension results from the THALASSA study," Annals of Hematology, vol. 92, pp. 14851493, 2013. 


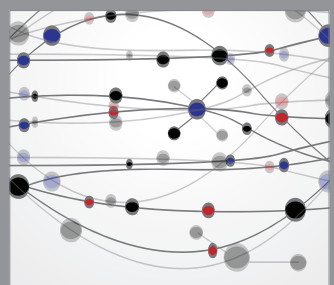

The Scientific World Journal
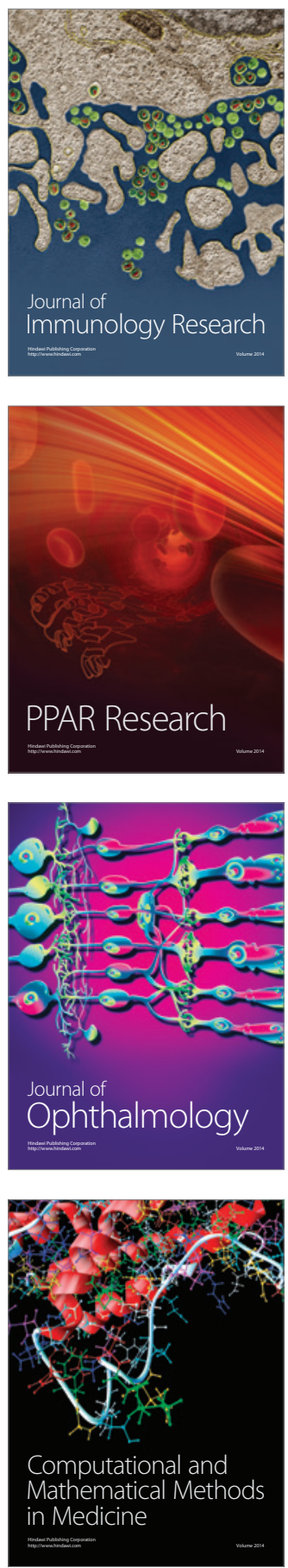

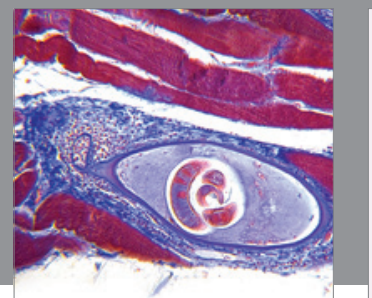

Gastroenterology

Research and Practice
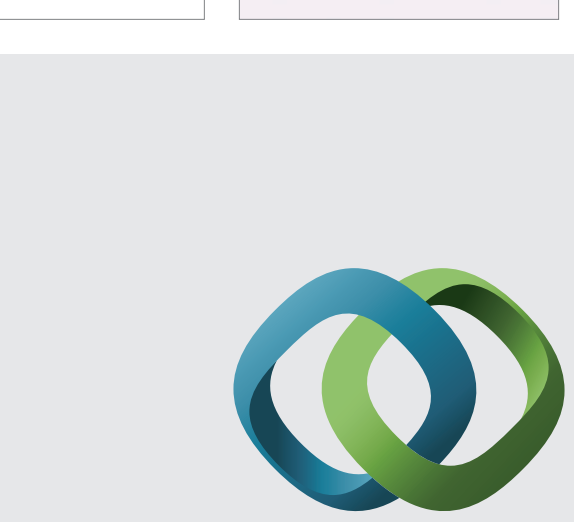

\section{Hindawi}

Submit your manuscripts at

http://www.hindawi.com
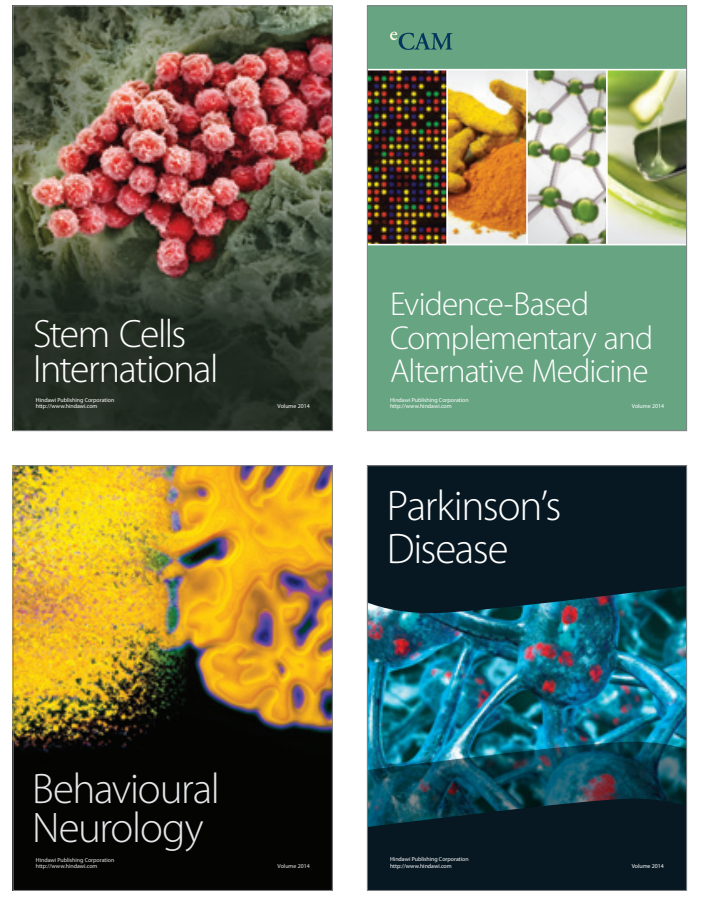
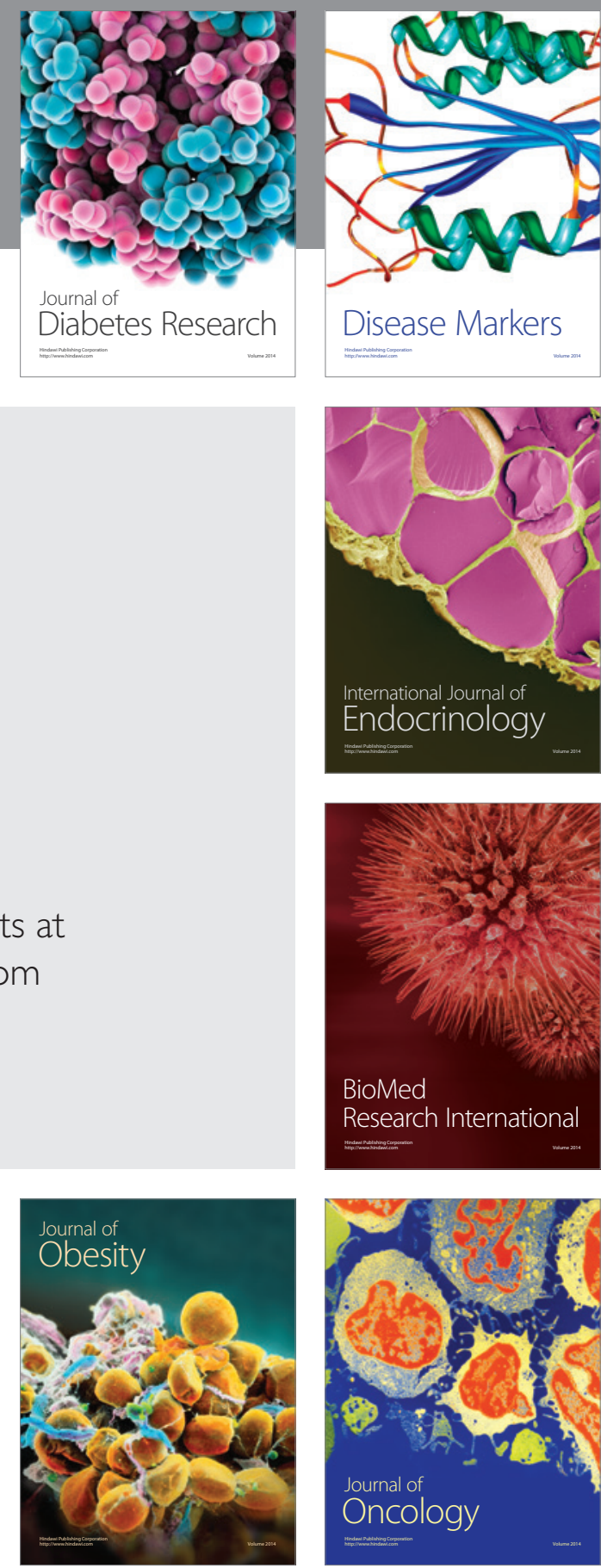

Disease Markers
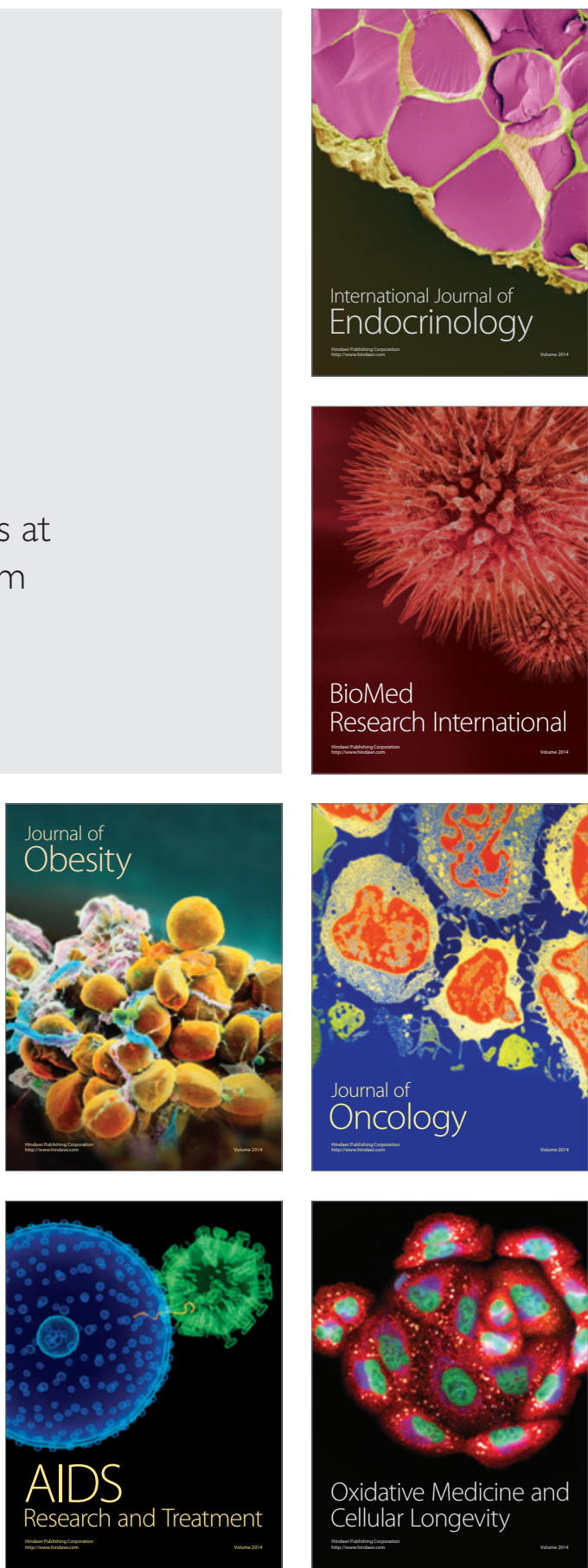